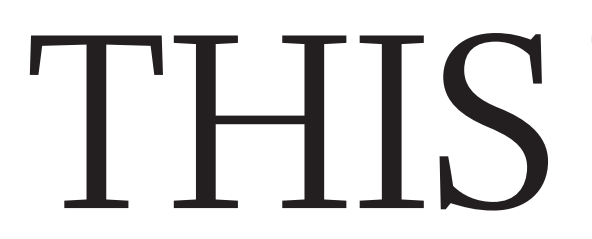

EDITORIALS

WORLD VIEW YVo de Boer on the lessons of the climate talks in Copenhagen $\mathbf{p . 4 7 7}$
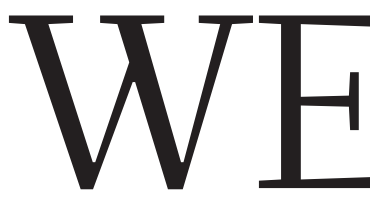

CHILDHOOD LOST Did Neanderthals simply grow up too fast? p.478
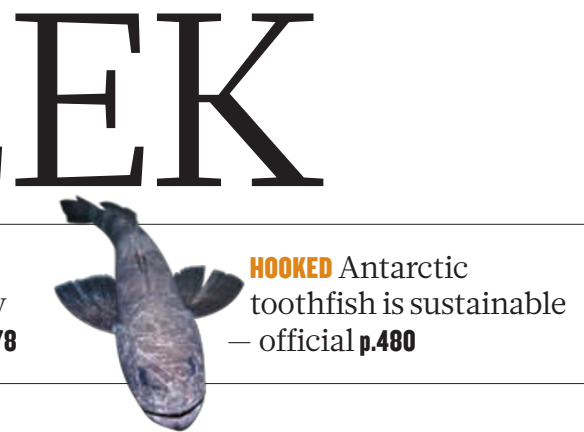

\title{
The party's over
}

Caffeinated alcoholic drinks, popular with students, are now being targeted by US regulators. But if government is serious about addressing alcohol abuse, it must confront more powerful foes.

$\mathrm{D}$ o alcohol and caffeine mix? The US Food and Drug Administration (FDA) has ruled they do not. Last week, FDA officials stamped on the makers of pre-mixed caffeinated alcoholic drinks, saying the products are "adulterated" by the addition of caffeine, which it said in this context was an "unsafe food additive".

The FDA's target was drinks such as Four Loko, a can of which packs the punch of a bottle of wine and two or three cups of coffee and may sell for less than US $\$ 3$. The food regulator, prompted by a wave of publicity for incidents in which young people were made seriously ill after over-indulging in the drinks, says manufacturers of Four Loko and six other caffeinated alcoholic drinks must remove the caffeine from their products, or their products from store shelves - or risk having them seized. Even before the decision was announced, Four Loko's maker, a small company called Phusion Projects in Chicago, Illinois, had agreed to remove the caffeine from its popular flagship product.

The drinks are said by the FDA to be of special concern because the caffeine counters the alcohol's soporific effects, leading largely young and inexperienced drinkers to drink more, and to perceive themselves as more capable, and less drunk, than they actually are. The science in this area is in its early days and incomplete, but several studies do show cause for concern. One measured the breath-alcohol levels of 623 drinkers - almost all of them students - leaving bars in a Florida university district in 2008. It found those who had consumed alcohol mixed with caffeinated energy drinks were three times more likely to leave the bar highly intoxicated, and four times more likely to intend to drive, compared with drinkers who consumed alcohol alone (D. L. Thombs et al. Add. Behav. 35, 325-330; 2010).

The FDA's move is a sensible precaution as far as it goes, but it can hardly be seen as serious government action to curb the death, disease and destruction caused by alcohol. The National Institute on Alcohol Abuse and Alcoholism, in Bethesda, Maryland, puts the US annual bill for the medical, social and economic cost of alcohol abuse at $\$ 235$ billion - almost $80 \%$ more than the costs related to all other addictive drugs combined. Alcohol, which damages virtually every organ system, claims more than 80,000 lives each year in the United States alone, and is responsible for about one-third of all fatal car crashes, half of all homicides, one-third of all suicides and one-third of all hospital admissions.

Nor are trends encouraging. In a 2007 survey of more than 100,000 15- and 16-year-olds in 35 European countries by the European Monitoring Centre for Drugs and Drug Addiction in Lisbon, Portugal, almost half said they had drunk heavily in the previous month.

The US makers of the caffeinated alcohol drinks, who made no secret of courting young people with their products, were an easy target for the FDA: small and obscure and without political muscle. The big global players, Anheuser-Busch InBev and MillerCoors, under pressure from state attorneys-general pulled their own caffeinated alcoholic drinks from the market in 2008, and agreed not to make them in future.

That they were willing to walk away without a fight speaks to the tiny sliver of US alcohol sales that such caffeinated drinks represent. Sales of alcoholic drinks are estimated to be worth about $\$ 100$ billion a year; by contrast, sales of Four Loko, the most popular of the FDAtargeted drinks, were just \$144 million over the past 12 months.

Government must look

far more seriously at curbing alcohol consumption.

— taking a leaf from the FDA's proposed FDA's proposed script for cigarette packaging - requiring bottles to be emblazoned with graphic photos of cirrhotic livers, oesophageal varices and smashed vehicles under prominent messages such as 'Alcohol Kills'.

The industry will, of course, fight tooth and nail against any such moves. And in the beginning at least, it may triumph, as strong-armed soft-drinks manufacturers have in forestalling 'soda taxes' aimed at combating obesity. But if policy-makers are serious about limiting the damage caused by problem drinking, they must work towards a day when alcohol abuse has the same pariah status as tobacco. Not only would this move save untold lives, it would make a great deal of scientific sense.

\section{Treated fairly?}

\section{Moves to price new pharmaceuticals sensibly shouldn't damage the industry's health.}

$\mathrm{E}$ urope has long had a love-hate relationship with the pharmaceutical industry. When politicians wish to boast of the hightech and knowledge-based economies they have fostered, they wheel out the profitable returns from drug companies. Yet when the public mood suits, those same politicians criticize the profits, and use them to justify calls for price cuts.

The price of medicines, especially costly new drugs, is again a hot topic in cash-strapped Europe. Several countries are weighing up new ways to determine both the cost and the value of such medicines. The move would have pleased Oscar Wilde, who famously remarked that a cynic knew the price of everything and the value of nothing; but the pharmaceutical giants are nervous.

Done well, novel pricing mechanisms could foster innovative 